\title{
A high resolution climatology of precipitation and deep convection over the Mediterranean region from operational satellite microwave data: development and application to the evaluation of model uncertainties
}

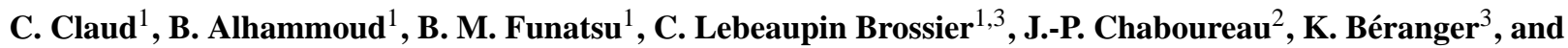 \\ P. Drobinski ${ }^{1}$ \\ ${ }^{1}$ Laboratoire de Météorologie Dynamique/IPSL, CNRS, UMR8539, Ecole Polytechnique, Palaiseau, France \\ ${ }^{2}$ Laboratoire d'Aérologie, University of Toulouse and CNRS, Toulouse, France \\ ${ }^{3}$ Ecole Nationale Supérieure de Techniques Avancées (ENSTA) - ParisTech, Unité de Mécanique, Palaiseau, France
}

Correspondence to: C. Claud (chclaud@lmd.polytechnique.fr)

Received: 5 December 2011 - Revised: 17 February 2012 - Accepted: 20 February 2012 - Published: 23 March 2012

\begin{abstract}
A new precipitation and convection dataset for the Mediterranean Basin, derived from operational satellite microwave data is documented. The dataset is derived from diagnostics that rely on brightness temperatures measured since 1999 in the water vapour absorption line (183$191 \mathrm{GHz}$ ). The dataset consists of twice-daily (a.m. and p.m.) and monthly maps of precipitation and convection occurrences on a $0.2^{\circ}$ lat $\times 0.2^{\circ}$ long grid for the area $25^{\circ}-$ $60^{\circ} \mathrm{N}, 10^{\circ} \mathrm{W}-50^{\circ} \mathrm{E}$. The instruments used so far are the AMSU-B sensor on the NOAA-15 to -17 satellites, and the MHS sensor on the NOAA-18 and -19 and METOP-2 satellites, with precipitation and convection available separately for the different sensors. The slightly different radiometric characteristics of MHS compared to AMSU-B do not affect significantly the continuity of the dataset. Precipitation and convection data from different sensors on different satellites are remarkably consistent, with generally small biases between the instruments. When larger biases appear, they can be explained either by the drifts in the satellite orbit, scan asymmetry, or temporal aliasing from insufficiently resolving the diurnal cycle of precipitation and convection. After a description of climatological aspects of rain and deep convection occurrence, the interest of this dataset to evaluate model uncertainties for simulating a high-impact weather event and for climatic regional runs over this area is illustrated.
\end{abstract}

\section{Introduction}

Precipitation is a major component of the climate system, with the availability of fresh water being vital to life on Earth. However, over most regions, it remains a challenging task to accurately document precipitation at a high spatial and temporal resolution. Still, in the densely-populated Mediterranean region, the hydrological cycle is a key environmental and socio-economical issue: the lack of readiness and mitigation strategies could result in critical situations, especially in the case of extreme events and inadequate evaluation of climate change impacts (e.g. Hulme et al., 1999; Giorgi, 2006; Gaertner et al., 2007). The specificities of the Mediterranean region, with a nearly closed sea surrounded by urbanized littorals and mountains from which numerous rivers originate, result in a lot of interactions and feedbacks between oceanic, atmospheric, and hydrological processes. These processes are, in turn, perturbed by anthropogenic activities and also play a predominant role in the regional climate and ecosystems. The Mediterranean climate is also influenced by both subtropical and mid-latitude climate dynamics and is therefore very sensitive to global climate change. Extreme weather events (heavy precipitation and flash flooding, drought, wind storms) regularly affect the region, causing heavy damages and human loss. These features underline the complexity of the hydrological cycle in the Mediterranean region. Only a long-term regular network measuring precipitation at a fine spatial and temporal resolution could provide a comprehensive view of precipitation

Published by Copernicus Publications on behalf of the European Geosciences Union. 
characteristics. Conventional instrumentation for measuring precipitation consists of networks of rain gauges and weather radar systems. Though measuring very accurately and continuously precipitation, they are unevenly distributed, mostly concentrated over land masses: as an example, Frei and Schär (1998) developed a precipitation climatology over the Alps with a resolution of about $25 \mathrm{~km}$ and one day. Over the oceans, however, the few existing gauges are located on islands and they are therefore subject to local influences. Polar-orbiting satellites appear thus as an unrivalled means to overcome these deficiencies. Specifically, the satellite data provided by the Advanced Microwave Sounding Unit (AMSU) radiometer allow to detect moderate and heavy precipitating areas (e.g. Kongoli et al., 2007; Vila et al., 2007; Surussawadee and Staelin, 2009; Di Tomaso et al., 2009; Laviola and Levizzani, 2011). This takes advantage of the fact that AMSU observations (a) are available on several platforms (five NOAA platforms and Metop-2) and thus offer a good temporal sampling, (b) allow a screening of precipitation over the whole of the Mediterranean Basin, including the sea where in-situ observations are scarce, and (c) have a fine spatial resolution ( $16 \mathrm{~km}$ at nadir). The use of observations from various platforms over a rather long period of time (here since 1999), however, rises a number of issues like the consistency between the radiometers and the possible drift in the satellite orbits. In our specific case, an additional issue is related to the fact that on recent platforms, the AMSUB radiometer has been replaced by the Microwave Humidity Sounder (MHS), which slightly differs from its predecessor by the frequency of two channels (one being used in the present study) out of five. The agreement between the two radiometers for diagnosing precipitation and convection needs therefore to be assessed.

The present work is a contribution to the HyMeX (HYdrological cycle in the Mediterranean EXperiment) program, which aims at better understanding and quantifying the hydrological cycle and related processes in the Mediterranean, with emphasis on high-impact weather events, inter-annual to decadal variability of the Mediterranean coupled system, and associated trends in the context of global change (Drobinski et al., 2010, 2011). Its goal is to better characterize the occurrence of precipitation and convection over the Mediterranean Basin over a long period of time. In Funatsu et al., 2009, results based on one satellite (NOAA-16) for the period 2001-2007 were discussed. In this paper, we extend the period to more than a decade and consider the observations of six satellites; besides, possible applications for evaluating meteorological and climate models, a key issue of the Medup program ("Forecast and projection in climate scenario of Mediterranean intense events: Uncertainties and Propagation on environment") that was a preparation of HyMeX, are presented.

The paper is organized as follows: Sect. 2 describes microwave satellite observations, the diagnostics used to detect precipitation and convection, and the properties of the dataset. After a general description of the climatology of rain and deep convection, the different issues raised by the construction of the dataset are addressed in Sect. 3. A possible use of this record for model uncertainties estimation is illustrated in Sect. 4. Finally, in Sect. 5, the results of the study are summarized and discussed.

\section{Satellite data and precipitation diagnostics}

\subsection{Data and pre-processing}

AMSU is a cross-scanning microwave instrument flying on board NOAA and MetOp polar-orbiting satellites since late 1998 (see Table 1, which provides a summary of the platforms that carry the AMSU-B/MHS instruments). It consists of two modules: AMSU-A and AMSU-B (replaced by MHS, on recent platforms; Table 2). AMSU-A, with 12 of 15 channels in the molecular oxygen frequencies (50$58 \mathrm{GHz}$ ) mainly designed for atmospheric temperature profiles retrieval, is not used in this study. AMSU-B/MHS has two atmospheric window channels (at 89 and $150 / 157 \mathrm{GHz}$ ) and three channels centered in a water vapour absorption line (183-191 GHz). Though this sounder was designed for optimal moisture retrieval, a number of studies have shown its utility for rainfall detection (e.g. Laviola and Levizzani, 2009). The instrument has a swath width of approximately $2300 \mathrm{~km}$, with 90 individual measurement pixels along the swath. Near-nadir instantaneous field of view of AMSUB/MHS is of $16 \mathrm{~km}$, while it is around $36 \mathrm{~km}$ for the largest viewing angles (Goodrum et al., 2000). Further details on the instruments can be found in the NOAA's KLM User's Guide available online at http://www2.ncdc.noaa.gov/docs/ $\mathrm{klm} /$. Because of the different equatorial crossing times and in spite of the drift of some satellites (Fig. 1), this configuration offers a very good temporal sampling of any region in the world and therefore of the Mediterranean Basin. While two observations per day are available during the first months of 1999 , there are on average six observations per day after mid-2002.

In this study, we used level1c AMSU-B/MHS brightness temperature (BT), which means that BT is pre-processed, calibrated, and navigated through the ATOVS (Advanced Tiros Operational Vertical Sounder) and AVHRR (Advanced Very High Resolution Radiometer) Pre-processing Package (AAPP) software. Early NOAA-15 observations suffered from antenna interference problems during the period 19981999 (Mo, 1999). This problem has been corrected subsequently, however scan asymmetries with respect to the angle of view in NOAA-15 AMSU-B can be large (Buehler et al., 2005), and therefore the diagnostics for year 1999 are considered as less reliable than those after 2000. In addition, following Funatsu et al. (2008), BT is re-sampled without smoothing to a regular horizontal grid of $0.2^{\circ} \times 0.2^{\circ}$ (about $20 \mathrm{~km}$ ), using a weighting of $1 / r^{2}$, where $r$ is the distance 
Table 1. List of platforms carrying AMSU-B/MHS radiometers and major characteristics: launch dates, LTAN (Local Time Ascending Node) at the time of the launching of the satellite and status of AMSU-B/MHS channels.

\begin{tabular}{lllll}
\hline Platform & Radiometer & Launch Date & LTAN & status \\
\hline NOAA-15 & AMSU-B & 13 May 1998 & $19: 20$ & Channels 3, 4, 5 failed Aug 2010 \\
NOAA-16 & AMSU-B & 21 Sep 2000 & $14: 24$ & Interference problems after 2007 \\
NOAA-17 & AMSU-B & 24 Jun 2002 & $22: 25$ & Channels 3, 4, 5 off since 13 Jan 2010 \\
NOAA-18 & MHS & 20 May 2005 & $13: 41$ & \\
Metop-2 & MHS & 19/10/2006 & $21: 30$ & \\
NOAA-19 & MHS & $06 / 02 / 2009$ & $13: 43$ & Degraded signal for channels 3 and 4 \\
& & & & between August and December 2009 \\
\hline
\end{tabular}

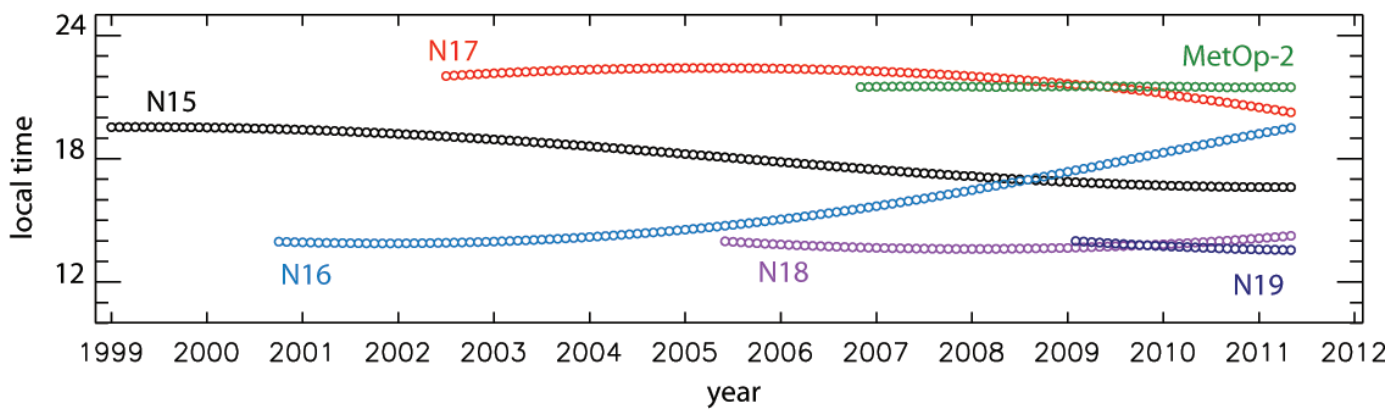

Fig. 1. Equator crossing-times of the ascending nodes of the satellites that carry AMSU-B/MHS sounders. Note that Metop-2 is maintained in stable orbit.

Table 2. Frequencies of AMSU-B and MHS channels.

\begin{tabular}{lll}
\hline $\begin{array}{l}\text { Channel } \\
\text { Number }\end{array}$ & $\begin{array}{l}\text { AMSU-B Center } \\
\text { Freq. (GHz) }\end{array}$ & $\begin{array}{l}\text { MHS Center } \\
\text { Freq. (GHz) }\end{array}$ \\
\hline 1 & 89 & 89 \\
2 & 150 & 157 \\
3 & $183 \pm 1$ & $183 \pm 1$ \\
4 & $183 \pm 3$ & $183 \pm 3$ \\
5 & $183 \pm 7$ & 190 \\
\hline
\end{tabular}

of the actual data point to the fixed grid point. Consecutive satellite passes covering the domain of $25^{\circ}-60^{\circ} \mathrm{N}, 10^{\circ} \mathrm{W}-$ $50^{\circ} \mathrm{E}$ are concatenated in their descending and ascending motions providing, for each satellite, twice daily BT information.

\subsection{Moderate rain and deep convection diagnostics}

AMSU-B/MHS moisture channels (3 to 5) detect the presence of hydrometeors through the scattering of radiation which lowers the brightness temperature compared to its surroundings (Greenwald and Christopher, 2002). Based on this property, Funatsu et al. (2007) showed that a combination of channels 3 and 5 of AMSU-B can detect precipitating areas; a BT difference of channels 3 minus 5 (hereafter, B3m5) equal to or larger than $-8 \mathrm{~K}$ was found to correspond statistically to a rainfall of at least $10 \mathrm{~mm}$ in $3 \mathrm{~h}$ when compared to the Tropical Rainfall Measuring Mission (TRMM) 3-hourly accumulated precipitation product over the Mediterranean Basin (product 3B42). Areas of deep convection are detected using a criterion initially devised to identify convection in the tropical regions (Hong et al., 2005), called the "deep convective threshold" (DCT). It is defined such that B3m5, B4m5 and B3m4 (i.e. AMSU-B/MHS channels 3 minus 5, 4 minus 5 , and 3 minus 4 , respectively) are simultaneously equal to or larger than zero. When compared with TRMM data, DC (Deep convection) was found to correspond in the Mediterranean region to an accumulated rainfall of at least $20 \mathrm{~mm}$ in $3 \mathrm{~h}$ in more than $50 \%$ of the cases. Both thresholds (10 and $20 \mathrm{~mm}$ in $3 \mathrm{~h}$ ) were validated for rain detection in the Mediterranean over surfaces free of snow or ice (Funatsu et al., 2007) with radar and rain gauges from meteorological ground stations for selected heavy precipitating events. In addition, despite the fact that the sensitivity of these channels to the underlying surface is reduced (e.g. Deeter and Vivekanandan 2005), over snow-covered areas or very cold surfaces, these thresholds alone may underperform in discriminating between frozen hydrometeors and a cold surface under a clear sky. Indeed, in very dry and cold atmospheric conditions, channels 3 to 5 are not totally opaque to the surface and the BT depression due to snow on the ground is 

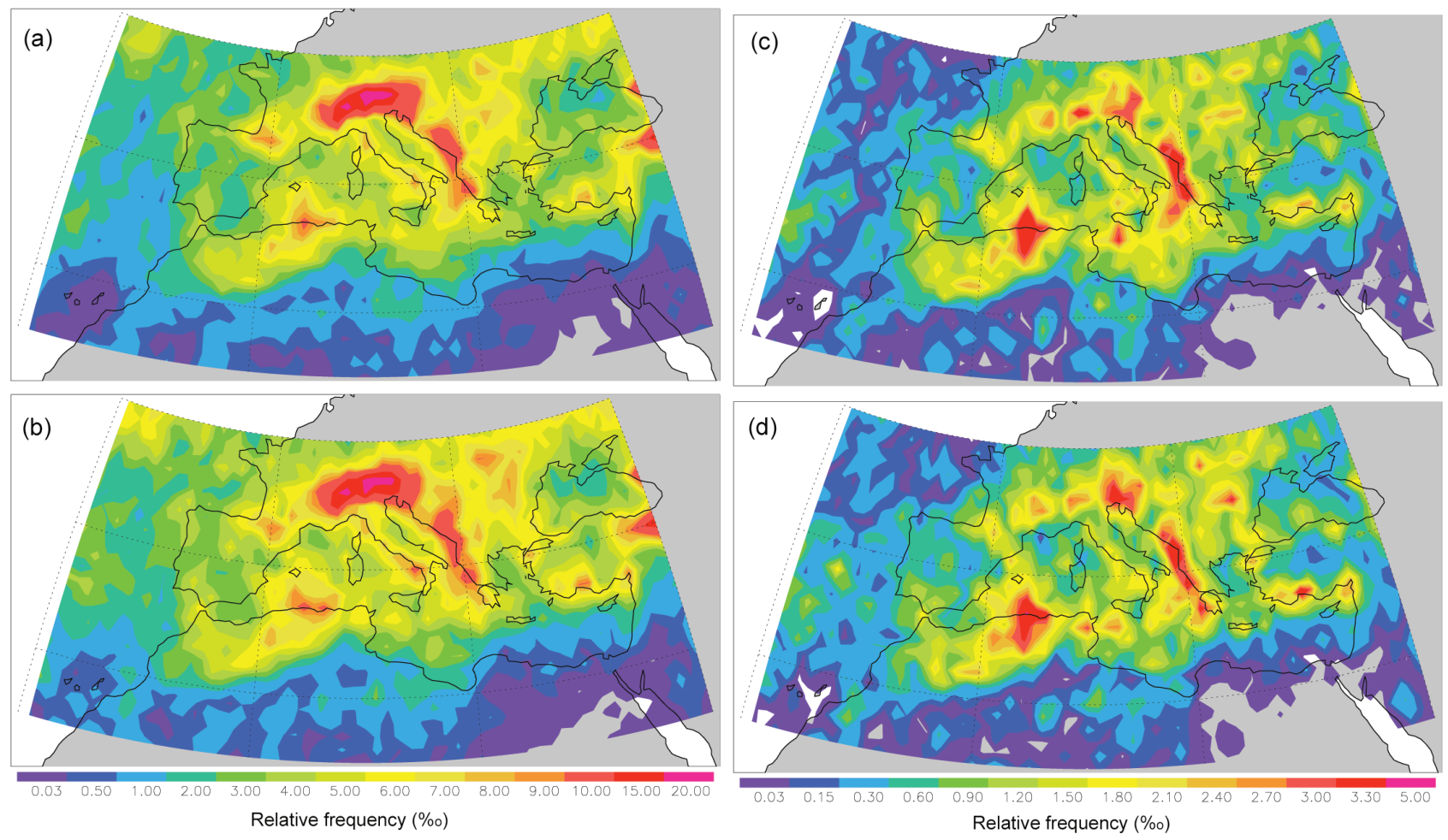

Fig. 2. Spatial distribution of relative frequency (in parts per thousand) of rain (a-b) and deep convection (c-d) at a $1^{\circ} \times 1^{\circ}$ grid for the period 2007-2009 from NOAA-17 (a-c) and Metop-2 (b-d).

of the same order of magnitude as the scattering signal by frozen hydrometeors (see e.g. Fig. 2 of Laviola and Levizzani, 2011). Over such areas, we use an additional constraint that a precipitating region must attain an upper-tropospheric humidity (UTH) relative to ice of at least $70 \%$. This UTH was calculated using AMSU-B/MHS channel 3 based on Buehler and John (2005). As shown by Funatsu et al. (2009), this restrains the false positive detection of precipitation, but this also results in a significant underestimation of precipitating events especially during wintertime. Using the same set of coefficients for all satellites for calculating UTH may also be problematic. To try to cope with these issues, lately, tests were performed in order to use independent information on the presence of snow, based on the ERA-I reanalyses (Dee et al., 2011). Though some adjustments may still be necessary, results are promising. In the following, all the results are based on the UTH criterion, except Fig. 3, which makes use of ERA-I information. The reason for that is that we wish to compare this figure to the results of a numerical simulation in which no difference is made between the different types of surfaces (Sect. 4b).

\subsection{Dataset properties}

The climatology consists of precipitation and deep convection occurrences in the domain $25-60^{\circ} \mathrm{N}, 10^{\circ} \mathrm{W}-50^{\circ} \mathrm{E}$ at a spatial resolution of $0.2^{\circ}$ latitude $\times 0.2^{\circ}$ longitude. It is important to note here that there is no attempt to determine a rain rate as proposed by other authors (e.g. Kongoli et al., 2007; Vila et al., 2007; Surussawadee and Staelin, 2009; Di Tomaso et al., 2009; Laviola and Levizzani, 2011). The weak correlation of scattering intensity and instantaneous rain rate at the surface (e.g. Bennartz and Petty, 2001) and saturation issues (e.g. Lima et al., 2007) might indeed lead to an underestimation of large rain rates associated with severe events, which are of special interest in the HYMEX project. This explains why we have favoured an approach in which we detect deep convection characteristic of those events, as well as moderate rain. For each satellite, twice-daily (a.m. and p.m.) occurrences of rain and DC are available for each gridpoint, from which monthly, seasonal, and annual climatologies can be constructed. Severe issues with one of the three channels used for deriving the diagnostics (see last column of Table 1) led to a stop of the production. As an example, NOAA-17 diagnostics are only available until December 2009. Because only 5 months of NOAA-19 data exist (from March until July 2009), they are not discussed in this paper. In spite of these limitations, a huge advantage of this dataset consists of its high spatio-temporal resolution together with its global availability, including over problematic surface backgrounds such as coastlines and snow, as will be demonstrated below. 

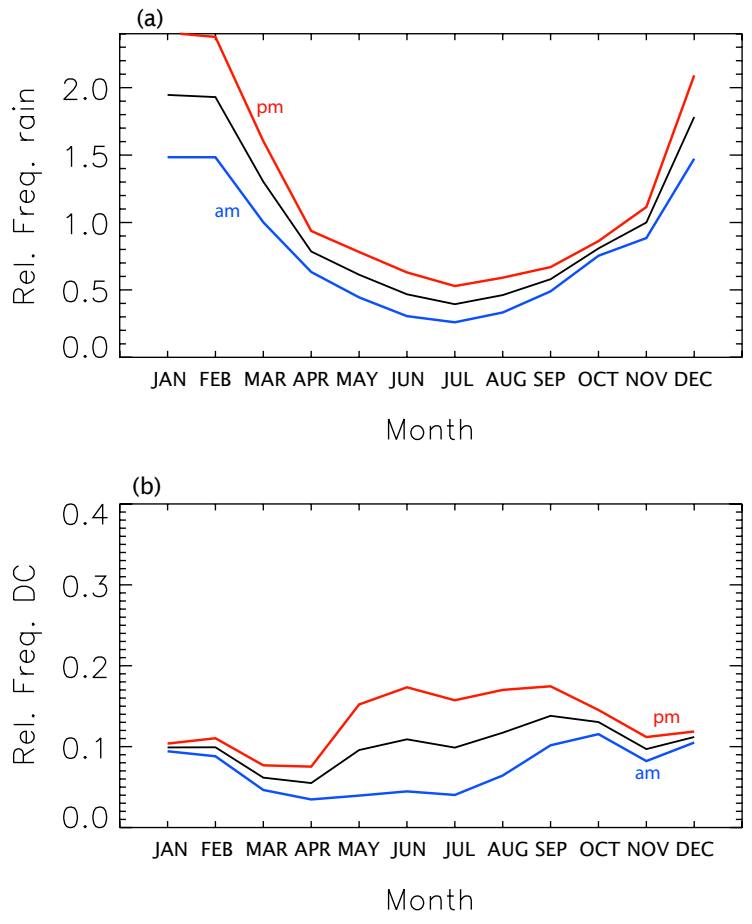

Fig. 3. Daily (in black), a.m. (= descending, in blue) and p.m. (= ascending, in red) seasonal cycle of (a) rain and (b) DC relative frequency based on NOAA-17 observations, 2003-2008. Values are averaged over the whole basin.

\section{Results}

\subsection{Rain and DC climatology}

Figure 2 provides rain and DC climatologies obtained over the period January 2007-December 2009 based on NOAA17 (Fig. 2a-c) and Metop-2 (Fig. 2b-d) satellites at a spatial resolution of $1^{\circ} \times 1^{\circ}$, respectively. This period has been chosen because (a) the two satellites have a close equatorial crossing time, and (b) it is representative of a longer period (see e.g. Fig. 9a, valid for January 2003December 2008). Each value corresponds to an average number of rain occurrences, considering the 25 gridpoints (from the original $0.25^{\circ} \times 025^{\circ}$ ) centered around a full degree latitude/longitude $1^{\circ} \times 1^{\circ}$ gridpoint. For example, the relative occurrence of rain at $\left(35^{\circ} \mathrm{N}, 35^{\circ} \mathrm{E}\right)$ is the sum of rain occurrences in the window $\left(34.5^{\circ} \mathrm{N}-35.5^{\circ} \mathrm{N}, 34.5^{\circ} \mathrm{E}-\right.$ $35.5^{\circ} \mathrm{E}$ ) divided by 75 (total number of gridpoints times three, because we averaged over 3 yr). First of all, the maps displayed Fig. 2 for the two satellites exhibit a high degree of similarity in terms not only of large-scale structures, but also fine-scale features. Moreover, they both indicate that, in addition to the well-known latitudinal gradient pattern (higher/lower values to the north/south; e.g. Mariotti et al., 2001), rain occurrence patterns are complex. These patterns are briefly described below, with a more accurate description of the characteristics at different scales (inter-annual,
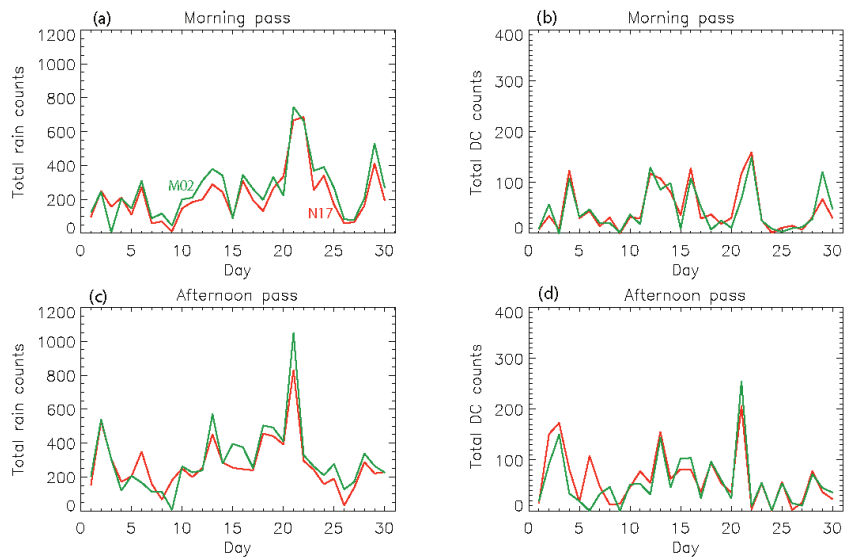

Fig. 4. Time series of October 2007 total (left) rain and (right) DC counts over the Mediterranean Basin for (top) morning and (bottom) afternoon NOAA-17/AMSU-B (N17, in red) and Metop-2/MHS (M02, in green) passes.

seasonal, intra-seasonal, diurnal) being the subject of a companion paper. Rain occurrence is minimal to the south and to the southeast of the region. Rain and DC are generally more frequent over land than over sea, and over land their occurrence is tied to the orography (Alps, Pyrenees, Atlas...). Over sea, rainfall and DC occurrence is more widespread in the western part of the Mediterranean Sea than over the eastern part, but there are a number of local specificities. More/less frequent rain is observed to the west /east of the continents (e.g. Italy, Greece, but also Sardinia and Sicily). Rain and DC are also more frequent to the south of Turkey and in the Algerian Sea. Rain and DC occurrence maxima along the Turkish coast are related to the preferred path of cyclones during summer and autumn (Flocas et al., 2010; their Fig. 2). During summer, systems occur there due to the combined position of the subtropical high that prevails over the whole Mediterranean and the Pakistan low that extends over the Eastern Mediterranean (Ziv et al., 2004). During autumn, the systems are probably related to the warmer sea surface temperatures (Flocas et al., 2010). The large values of DC and rain frequency over North Africa and in the Algerian Sea have two causes: over land, their maximum occurs in summer because of thunderstorms, while over sea, the maximum is during fall (Funatsu et al., 2009), likely in relationship with cyclone paths (Campins et al., 2000; Bartholy et al., 2009). In the northernmost part of the Mediterranean Sea, it is over the Gulf of Lions and over the Aegian Sea between Greece and Turkey that rain and DC are the less frequent. To the south, rain is more frequent in the Gulf of Sidra and in the Ionian Sea than elsewhere. The high values in the Ionian Sea likely result from cyclones that have followed a southeastward path along the Adriatic coast and others that have formed over Southern Italy (Trigo et al., 2002). 


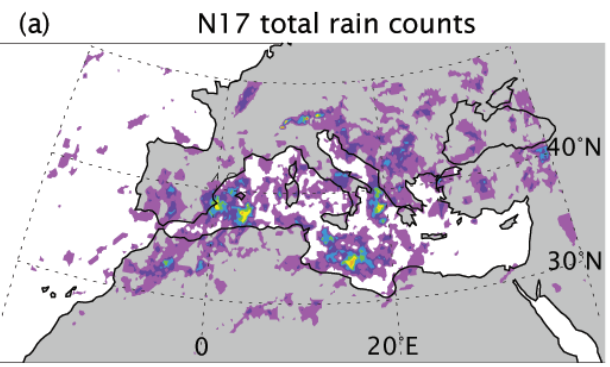

(b) $\quad \mathrm{N} 17$ total DC counts
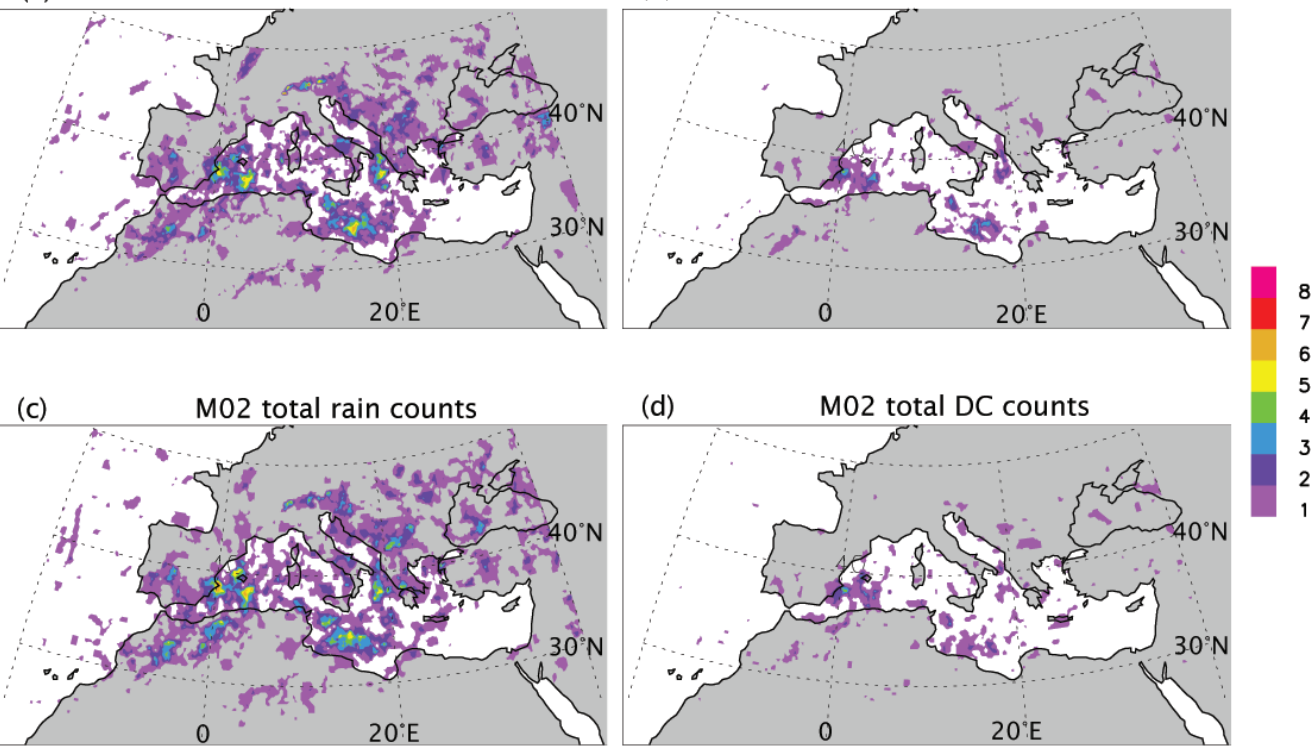

(e) Diff (N17-M02) rain counts
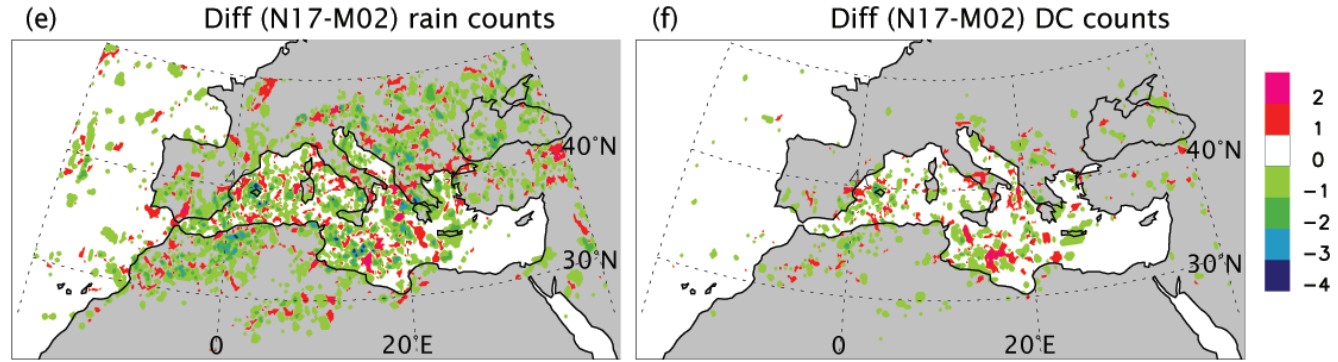

Fig. 5. Spatial distribution of October 2007 (left) rain and (right) DC counts over the Mediterranean Basin for (top) NOAA-17/AMSU-B and (middle) Metop-2/MHS passes, and (bottom) their difference.

This annual distribution results from an important seasonal cycle of rain and DC as illustrated in Fig. 3 for daily, morning (= descending), and evening (= ascending) passes. For NOAA-17, the morning window is 06:00-13:00 UTC, while the evening one is 13:00-23:00 UTC. We recall that, for this figure, the presence of snow was inferred from ERA-I, in order to reduce the underestimation of precipitating events during winter. On average over this 6-yr period (2003-2008) and at the scale of the basin, rain occurrence is maximum during winter and minimum during summer. Rain is always more frequent in the evening than in the morning, with large differences occurring during spring and summer. For this period, differences during wintertime are large too, but we have observed periods during which they were more reduced (not shown). The DC seasonal cycle is totally different, with a mean daily occurrence that is maximum in the period MayOctober and minimum in March-April. Unlike rain, there are differences between a.m. and p.m. cycles. In the case of a.m., DC occurrence is weak from March until July and maximizes in October. For p.m., the minimum is reached in
March-April, with largest values between May and September. The largest differences between a.m. and p.m. in terms of occurrence are observed during spring and summer. Funatsu et al. (2009) showed that there is also a clear pattern of seasonal shift in the location of DC, moving from mostly over land in the period April-August, to mostly over the sea in the period September-December. While the precipitation occurrence distribution is overall congruent with the climatology of rainfall amounts provided by the Global Precipitation Climatology Project, (GPCP; Adler at al., 2003) as shown by Funatsu et al. (2009), the considerable variations across the basin evidenced in our climatology are smeared in GPCP due to its coarser spatial resolution $\left(2.5^{\circ}\right)$.

\subsection{MHS/AMSU-B consistency}

On recent platforms, MHS has replaced AMSU-B. Because channel 5 of MHS is centred at a slightly different frequency than its AMSU-B counterpart (Table 2), the impact of this change on the detection of rain and deep convection 

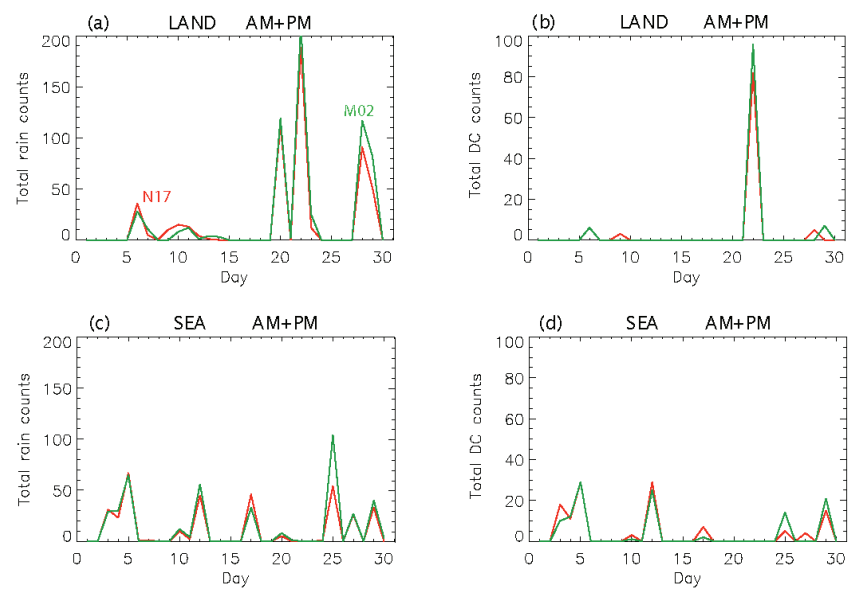

Fig. 6. Time series of October 2007 total (left) rain and (right) DC counts over (top) a land and (bottom) a sea box (morning + afternoon) NOAA-17/AMSU-B (in red) and Metop-2/MHS (in green) passes. The coordinates of the land box are $\left(42^{\circ} \mathrm{N}-45^{\circ} \mathrm{N}, 20^{\circ} \mathrm{E}-\right.$ $\left.25^{\circ} \mathrm{E}\right)$, those of the sea box $\left(38^{\circ} \mathrm{N}-42^{\circ} \mathrm{N}, 3.7^{\circ} \mathrm{E}-7.0^{\circ} \mathrm{E}\right)$.

has to be assessed, even if the results shown in Fig. 2 suggest that likely they are minor. According to Kleespies and Watts (2007), based on radiative transfer simulations for diverse atmospheric profiles, the brightness temperature bias between AMSU-B and MHS for channel 5 would be approximately $0.1 \mathrm{~K}$, with a standard deviation of also approximately $0.1 \mathrm{~K}$. A further evaluation, based on a larger sample, indicates that the differences between AMSU-B and MHS depend on the amount of water vapour in the atmosphere and range from -1 to $3 \mathrm{~K}$ (in the latter case when the atmosphere is very dry) (John et al., 2012). It has also been suggested that MHS could be more sensitive to convection than AMSU-B (Mo, 2006; Claud et al., 2010).

To examine the consistency between MHS and AMSU-B, Figs. 4a-d show the temporal evolution of global rain and DC counts, based on NOAA-17/AMSU-B and Metop-2/MHS and their difference for the month of October 2007. These counts correspond to the number of grid points for which rain (DC) was detected each a.m./p.m. Morning and afternoon passes are shown separately to account for possible diurnal differences. This month was selected, because rain and deep convections were present over the region throughout this period, making the comparison more meaningful. A very good agreement between the two instruments is observed for both rain and DC. No systematic difference appears, neither for rain nor for DC, with MHS-based rain and DC sometimes biased high and sometimes biased low compared to AMSUB, the differences remaining always minor (less than 200/100 points out of about 2 Millions for 1 month). Most of these differences can be ascribed to the different time of sampling (even within $1 \mathrm{~h}$-see Fig. 1), considering the high spatial and temporal variability of rainfall. To a certain extent, the crossscan characteristics of the instrument (each scan produces observations of different footprint size according to the viewing angle (Vila et al., 2007; Di Tomaso et al., 2009), may have also contributed to these differences (the same gridpoint can be viewed under a different viewing angle with NOAA17 and Metop-2).

Spatial differences between NOAA-17/AMSU-B and Metop-2/MHS are shown in Fig. 5, which displays rain and DC counts, accumulated for each grid point over the month (NOAA-17/AMSUB in Fig. 5a, Metop-2/MHS in Fig. 5b), and the difference (Fig. 5c). Again, no systematic contrast between land and sea or north/south in relation to the amount of water vapour is observed. The temporal evolution of rain and DC counts for an only land box (top panels) and an only sea box (bottom panels) is presented in Fig. 6. It confirms the high consistency between the two radiometers regarding the diagnostics used in this study. Similar results were obtained for other months and areas (not shown).

\subsection{Intersatellite differences}

Figure 7 provides multi-year variations in rain and DC detected by the AMSU-B aboard NOAA-15 to 17 satellites and the MHS aboard NOAA-18 and Metop-2. The whole Mediterranean region has been considered. Figure 7 shows a fair agreement between all sensors, both in terms of rain and DC, except for NOAA-16 after 2007-2008. Correlation coefficients determined over the common period of the considered satellites reflect this point, with values ranging from 0.61 (between NOAA-15 and NOAA-16) to 0.92 (between Metop-2 and NOAA-18) for rain and from 0.73 (between NOAA-15 and NOAA-16) to 0.93 (between NOAA-17 and NOAA-18) for DC.

Concerning specifically NOAA- 16 , we found that the rain overestimation, especially after 2008 , was caused by problems in BT of channels 4 and 5. A thorough investigation reveals that the BT for the first 20 pixels (out of 90; see Sect. 2.1) was systematically biased high. This left-right asymmetry has already been reported in the literature by Surusswadee and Staelin (2010) and is related to a residual uncorrected radio-frequency interference (in spite of initial corrections made by NOAA). Because of the small overlapping between consecutive passes over the region of interest (significant overlapping could have permitted an a posteriori correction in BT), and the potentially large temporal variations in BT, no reliable correction to these pixels is possible. In addition, removing the 20 affected pixels would have led to gaps, preventing a $0.2^{\circ}$ lat $\times 0.2^{\circ}$ long re-sampling as required in our method; therefore, the analysis of NOAA-16 dataset was done until the end of 2007.

Most of the remaining differences in Fig. 7 can be explained by the different sampling times and the diurnal variations in rain and DC. This is the case for NOAA15, and particularly DC. After January 2008, the satellite drift was such (Fig. 1) that the time of the orbits that were kept for forming a.m. and p.m. gridded fields was modified 

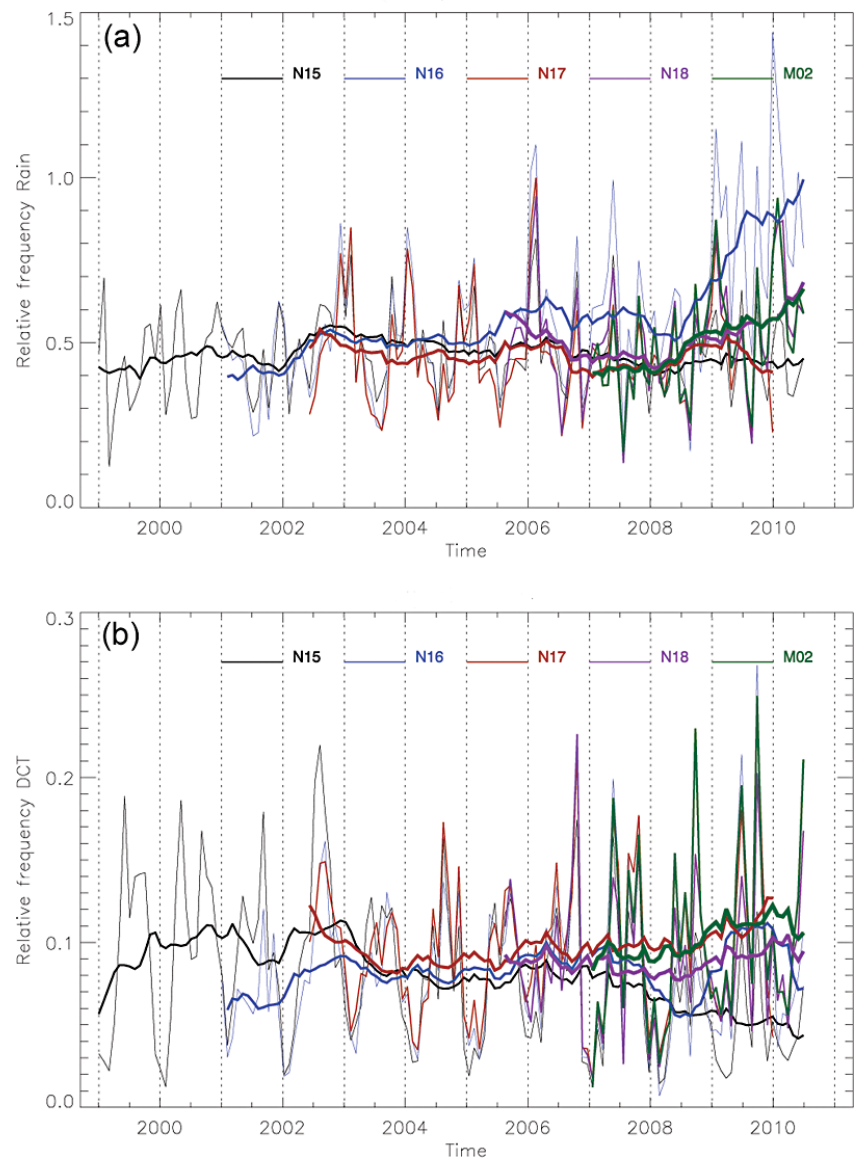

Fig. 7. Monthly and 12-month moving average (in bold) time series of (a) rain and (b) DC relative frequency anomalies from NOAA-15 to 18 and Metop-2 satellites.

(otherwise gaps would appear either to the west or the east of the basin): instead of considering passes in the range 02:00-09:00 UTC/12:00-19:00 UTC for a.m./p.m., passes between 01:00-08:00 UTC/11:00-18:00 UTC, respectively, were kept. As a result, ascending (= p.m.) DC decreased significantly, which indirectly means that deep convection at the scale of the Mediterranean Basin is significant in the range 18:00-19:00 UTC, but weak in the range 11:00-12:00 UTC. Unlike DC, rain does not seem to be affected by this change, because moderate rain is often linked to upper-level systems as evidenced by satellite observations (Chaboureau and Claud, 2006; Funatsu et al., 2008): over the period 20012006, Funatsu et al. (2008) found that, on average, for $80 \%$ of the cases where rain was present, there was a upper-level anomaly present with no difference between a.m. and p.m. Finally, the decrease in NOAA-17 rain after mid-2009 stems to a large extent from the moving average.

Figure 7 also indirectly suggests inter-annual and intraseasonal variability, even at the scale of the whole basin; for example, the first months of 2006 showed higher rain values, while spring and summer 2003 were persistently dry, consistent with the summer heat wave that hit Europe that year and the spring conditions that preceded it (Fischer et al., 2007). DC was less important in the years 2003-mid-2006 than before and after. As already noted, these variations will be investigated more specifically in another paper and are not discussed in details here.

\section{Potential for evaluating model uncertainties}

As mentioned earlier, the objective of this section is not to precisely evaluate a given simulation in terms of precipitation, but rather to illustrate how the dataset described in this paper can be used to validate a numerical simulation. First, we show how the forecast of a high-impact weather event can be assessed through a model-to-satellite approach. Then, we use the multi-year (2003-2008) output of a long-term simulation of the coupled numerical system MORCE (Model of the Regional Coupled Earth system) to compare the seasonal cycles of rain and convective rain in this model and in the dataset.

\subsection{Verification of meteorological forecasts}

An example of application of this dataset for verifying meteorological forecasts is shown for an intense cyclogenesis, leading to the formation of a tropical-like storm or medicane (Mediterranean "hurricane") over southeastern Italy (e.g. Claud et al., 2010). The forecast of the medicane was performed with the nonhydrostatic model Meso-NH (Lafore et al., 1998) using the two-way interactive gridnesting method with triply nested grids, with a horizontal grid spacing of 32, 8 and $2 \mathrm{~km}$. The experiment started on 25 September at 12:00 UTC from the European Centre for Medium-Range Weather Forecasts analyses. It was then integrated until 26 September at 18:00 UTC. For further details on the simulation setup, the reader is referred to Chaboureau et al. (2012).

The AMSU-B/MHS diagnostics presented above were used here to evaluate the quality of numerical simulation in the observation space using the so-called model-to-satellite approach. Such an approach consists of calculating the brightness temperatures at AMSU-B/MHS wavelengths using a radiative transfer model (e.g. Chaboureau et al., 2000). Note that the AMSU observations were interpolated onto the 8-km Meso-NH grid on which the evaluation was performed. In Fig. 8, the evaluation of the Meso-NH simulation is shown at three stages of the development of the mesocyclone into a medicane. The figure shows, both for the observations and Meso-NH, B3m5 BT (rain is detected whenever B3m5 is equal to or larger than $-8 \mathrm{~K}$ ), and deep convection areas, which are depicted as filled circles. On 25 September 2006 in p.m. (left panels), a deep convection was observed along the western Italian coast and over the Ionian Sea (Fig. 8a). While 

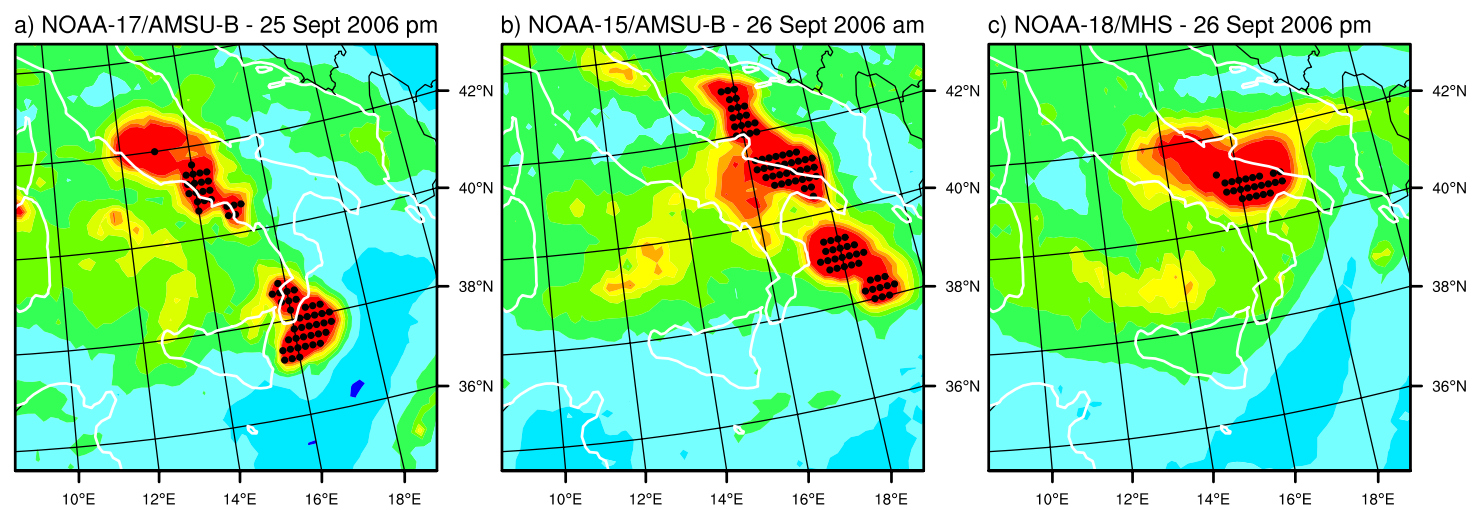

d) MESO-NH - 25 Sept 20062100 UTC
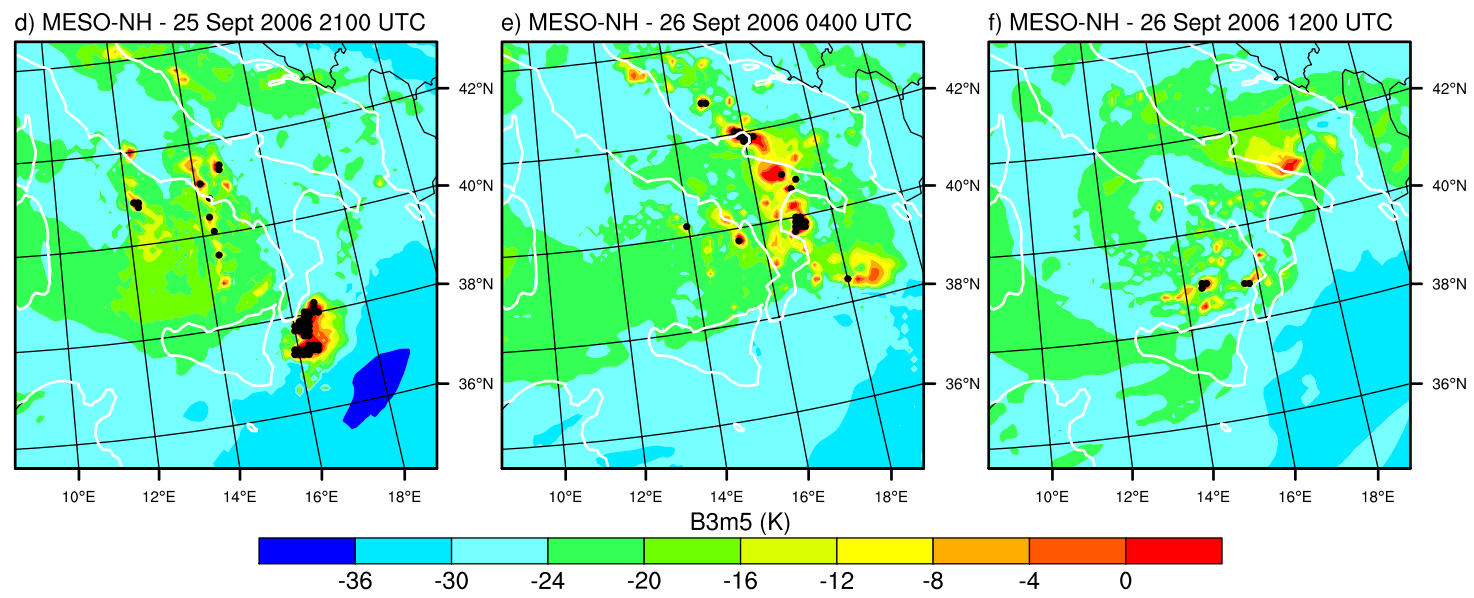

Fig. 8. B3m5 BT (K, shading) and DC (filled circles) for (left) 25 September 2006 afternoon, (centre) morning, and (right) 26 September 2006 afternoon obtained from (top) AMSU-B/MHS observations, and (bottom) Meso-NH forecasts. Rain is detected whenever B3m5 BT values are equal to or larger than $-8 \mathrm{~K}$ and deep convection areas are depicted as filled circles.

its predicted convection was less ubiquitous over mainland Italy than observed, the Meso-NH simulation forecasted deep convection over the Ionian Sea correctly (Fig. 8d), associated with a mean sea level pressure (MSLP) minimum of $1002 \mathrm{hPa}$ (not shown). In particular, the circular structure associated with the mesocyclone was well reproduced. On 26 September in a.m. (Fig. 8b-e), two areas of convection were observed with DC, one organized in a line over Apulia and the Adriatic Sea, and the other with a circular pattern over the Ionian Sea, which is a signature of the medicane. Again, the convective activity in the north of the domain was missed by Meso-NH. In these regions, snow dominates in the atmospheric column. As previously diagnosed by Meirold-Mautner et al. (2007), these discrepancies can be attributed to difficulties in accurately representing the radiative properties of snow (a mixture of air and ice particles) in the microwave region. Over the Ionian Sea where the most active cell is located, in the Meso-NH simulation, a circular pattern was predicted close to what was observed, but with a DC area underestimation. The good agreement obtained there with the observation corresponds to a region where graupel contents were much more important than snow ones, situations that generally arise in tropical conditions (Wiedner et al., 2004). The mesocyclone had then developed as a medicane with a shallow warm core and a MSLP minimum of $992 \mathrm{hPa}$. On 26 September p.m. (right panels), in the observation, B3m5 $>-8 \mathrm{~K}$ spread over Italy between $40^{\circ}$ and $42^{\circ} \mathrm{N}$ while DC persisted in a narrow sector, mostly over land (Fig. 8c). Observed DC was only marginally associated with the medicane, mainly located over sea. Areas with $\mathrm{B} 3 \mathrm{~m} 5$ is equal to or larger than $-8 \mathrm{~K}$ in the Meso-NH simulation were spatially more limited than in the observations, albeit at the right position, whereas no DC in connection with the medicane was simulated (Fig. 8f). At that time, the medicane had developed a full tropospheric warm core like a tropical storm and its MSLP minimum reached $986 \mathrm{hPa}$.

In conclusion, this example illustrates the interest of AMSU-B/MHS diagnostics to check the ability of a model to predict convection associated with an intense mesocyclone at the right place and time, a verification that would have been impossible otherwise due to the lack of adequate precipitation measurements. 

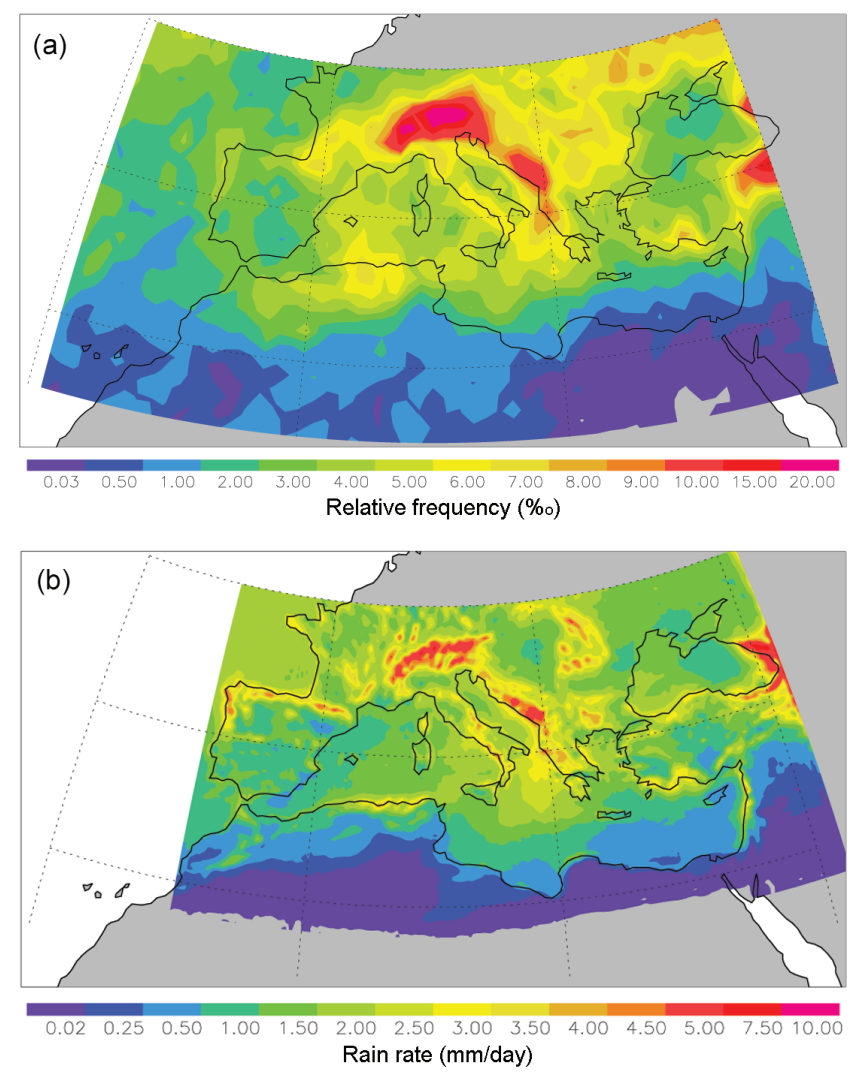

Fig. 9. (a) NOAA-17 rain occurrence (in $\%$ at a $1^{\circ} \times 1^{\circ}$ grid) and (b) MORCE rain rate (in mm day ${ }^{-1}$ ) for the period 2003-2008.

\subsection{Regional climatic runs evaluation}

For the description of the whole numerical platform and the experimental setup, we refered the reader to Drobinski et al. (2012). In brief, the numerical system was the MORCE (Model of the Regional Coupled Earth system), which was developed for process and climate studies, especially in the Mediterranean region. The atmospheric component was the Weather Research and Forecasting (WRF) model of the NCAR (Skamarock et al., 2008). The domain covered the Mediterranean Basin with a horizontal resolution of $20 \mathrm{~km}$ and 28 vertical sigma levels. The oceanic component was NEMO (Madec, 2008) and was used in a regional Mediterranean configuration called MED12 (Lebeaupin Brossier et al., 2011) with a $1 / 12^{\circ}$ horizontal resolution and 50 unevenly spaced Z-levels in the vertical. The ocean-atmosphere coupling consisted of Sea Surface Temperature (SST) and fluxes of heat (solar and non-solar), water and momentum exchanges between the two components. The exchange frequency and the field interpolation were realized through the OASIS coupler (Valcke, 2006), with a coupling frequency of $3 \mathrm{~h}$. The coupled experiment covered the period 1 January 1989-31 December 2008, and was forced by ERAInterim (Dee et al., 2011).
MORCE precipitation (in terms of annual mean rain rate) and AMSU rain occurrence fields are provided in Fig. 9 for the period 2003-2008. Because no rain rate was produced from AMSU-B/MHS, it is impossible to perform a direct comparison. In addition, gridpoints for which DC is detected do not all correspond to a single rain rate threshold value (see Fig. 8 of Funatsu et al., 2007). However, a qualitative comparison indicates a fair agreement between the two datasets with minimum values to the south of the region and maxima in connection with orography or for regions known to be chararacterized by large cyclonic activity (Sect. 2). Of special interest is the annual cycle of total rain and convective rain produced by the model (by convective rain, one means rain produced by the atmospheric convection parameterization (Kain, 2004) in the model), which is displayed Fig. 10a and $\mathrm{b}$ for morning (06:00-09:0012:00 UTC), evening (15:00-18:00-21:00 UTC), and daily (the average of a.m. and p.m.). The annual cycle of total rain is overall in fair qualitative agreement with the one of AMSU-B-derived rain occurrence (Fig. 3a) with a minimum in summer and a maximum during fall. In agreement with the observations, rain rate is generally larger in the evening than in the morning with large differences in spring and summer, but unlike the observations, the difference between a.m. and p.m. rain rate is weak from October until March. The simulated convective rain cycle (Fig. 10b) also shows a lot of similarities with the observed one (Fig. 3b) with a maximum in the period May-October, even if p.m. convective activity is relatively weaker in August-September and stronger in October compared to AMSU-B. As for rain, differences between p.m. and a.m. are weak during wintertime, while they are more significant in the observations.

\section{Summary and conclusions}

Precipitation at a high spatial and temporal resolution over the Mediterranean Basin and especially offshore remains not well-known (see e.g. Aznar et al., 2010). The purpose of this article is to present and document a new precipitation and convection occurrence dataset, based exclusively on newgeneration microwave satellite sensors. These sensors indeed permit a concomitant observation of convection/precipitation over land and sea at a temporal resolution higher than that of meteorological analyses (because these sensors are flown on several platforms) and with a very fine-scale spatial resolution. More specifically, the dataset is derived from diagnostics that have relied on brightness temperatures measured by channels 3 to 5 of the AMSU-B and MHS sensors in the water vapour absorption line (183-191 GHz) since 1999. The methodology to detect rain and convection from brightness temperatures has been validated by comparing diagnostics to rain gauges, radar and satellite (TRMM) measurements (Funatsu et al., 2007). Over snow-covered areas and very cold surfaces where the discrimination between frozen 

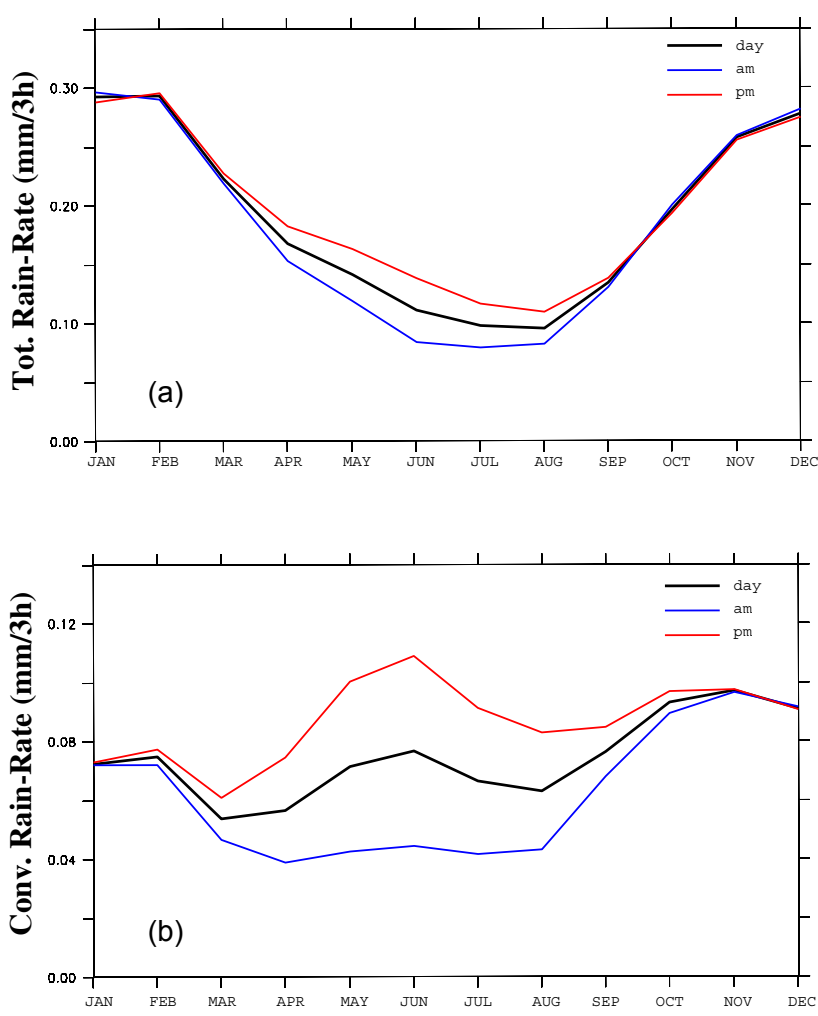

Fig. 10. Seasonal cycle of MORCE (a) total rain-rate and (b) convective rain rate for the 2003-2008 period averaged over the Mediterranean domain (as in Fig. 9b). Unit is $\mathrm{mm} / 3 \mathrm{~h}$. The cycle is shown separately for the morning (06:00-12:00 UC, blue), evening (15:00-21:00 UTC, red), and daily (average of a.m. and p.m., black).

hydrometeors and the surface is not easy, precipitation occurrence is underestimated (Funatsu et al., 2009). Improvements are still underway, like the use of ancillary information in ERA-I.

For each satellite, the dataset consists of twice-daily (a.m. and p.m.) and monthly maps of precipitation and convection occurrence on a global $0.2^{\circ}$ lat $\times 0.2^{\circ}$ long grid for the Mediterranean area, i.e. $25^{\circ}-60^{\circ} \mathrm{N}, 10^{\circ} \mathrm{W}-50^{\circ} \mathrm{E}$. The period covered so far goes from 1999 to 2010 and made use of NOAA-15 to -19 and Metop-2 satellites. Precipitation and convection occurrences are available separately for the different sensors. The slightly different radiometric characteristics of MHS compared to AMSU-B do not significantly affect the continuity of the dataset. Precipitation and convection occurrences from different sensors on different satellites are remarkably consistent, with small biases between the instruments. When larger biases appear, they can be explained either by the drifts in the satellite orbit (e.g. NOAA-15), scan asymmetry (NOAA-16 after 2007), or the diurnal cycle of precipitation and convection.

The global mean distribution of rain and convection occurrence in the dataset is in good qualitative agreement with precipitation climatologies in terms of large-scale structures.
The dataset also captures the yearly cycle of moderate rain and convection, consistently with expectations based on the known features of the general circulation. However, the distribution shows a number of regional structures features that are too fine to be captured by the most-widely used satellite-based precipitation climatologies (e.g. CMAP, Xie and Arkin, 1996; GPCP, Adler et al., 2003). Overall, rain and DC occurrence appear to be very much dependant on the cyclones path, in agreement with e.g. Jansa et al. (2001), with a strong link to the orography over land. This dataset is also promising by the number of details regarding the diurnal cycle in terms of rain and convection occurrences that have been illustrated using a single satellite. The use of several simultaneous satellites will enhance this knowledge, and is the subject of an ongoing study.

The interest of such a dataset for evaluating model uncertainties has been then illustrated in two different configurations (meteorological forecast and climate run). In the first case, data have been used to evaluate the quality of numerical simulations of precipitating systems through a model-tosatellite approach for a high-weather impact event that occurred over Italy. Such an evaluation involves the numerical simulation of brightness temperatures at AMSU-B/MHS wavelengths using a radiative transfer model and their comparison to the observations. While it allows an assessment of the model's physical parameterizations, it also provides new insights into precipitation events and processes (presence of deep convection). The second case consisted of a multi-year simulation. A big advantage in this case comes from the quasi-identical spatial resolution, which permits to compare not only the large-scale features, but also more local ones and thus validate rain distribution over islands or coastal regions. The seasonal cycles of total and convective rain have been compared for a.m. and p.m. While these comparisons have shown an overall fair agreement with the observations, they have also indicated some differences (like weaker differences between a.m. and p.m. during winter months), which will prompt further investigations in the future. The dataset offers many more possibilities, particularly with similar works at the regional scale (e.g. Mediterranean Sea /land only; Western/Eastern Mediterranean region...) and at different temporal scales (diurnal, monthly, seasonal). Also, the model-to-satellite approach will be adopted to evaluate the multi-year simulation, in combination with the more classical approach presented here.

Even with the disadvantage of not providing an instantaneous rain rate, the strength of this dataset is that it applies a uniform measurement strategy globally over the Mediterranean Basin, thus, allowing quantitative comparison of counts from diverse regions. We believe that this is a major step forward in characterizing the distribution of convective/non convective events and possibly trends. To this end, we plan to extend the temporal coverage of the dataset by processing the time series into the future. 
Acknowledgements. This work was carried out in the framework of the MEDUP project (Grant ANR-07-VULN-06-001), funded by the Vulnérabilité Milieux et Climat (VMC) programme of the National Research Agency (ANR) and was partly sponsored by the Chaire de Développement Durable of the Ecole Polytechnique and by Centre National d'Etudes Spatiales. AMSU data was obtained through the French Mixed Service Unit ICARE and CLIMSERV. The MORCE plateform was developed within the MORCE-MED project funded by the GIS "Climat, Environnement et Société", with granted access to the HPC resources of IDRIS (under allocation i2011010227). The MORCE coupled simulation and its validation contribute to the SiMed project (Simulation of the Mediterranean Sea) funded by Groupe Mission Mercator-Coriolis, to the Med-Cordex project (A COordinated Regional climate Downscaling EXperiment - Mediterranean region) funded by the World Climate Research Program, and to the HyMeX program (Hydrological cycle in the Mediterranean EXperiment) through INSU-MISTRALS support.

Edited by: G. Molinie

Reviewed by: S. Dietrich and another anonymous referee

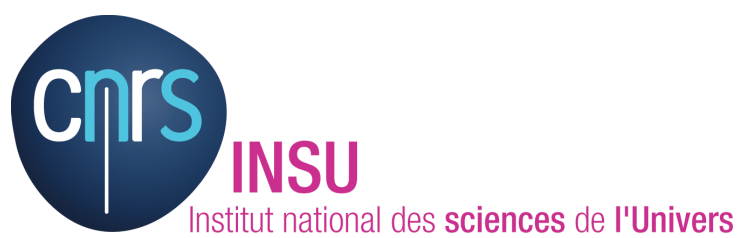

The publication of this article is financed by CNRS-INSU.

\section{References}

Adler, R. F., Huffman, G. J., Chang, A., Ferraro, R., Xie, P.-P., Janowiak, J., Rudolf, B., Schneider, U., Curtis, S., Bolvin, D., Gruber, A., Susskind, J., Arkin, P., and Nelkin, E.: The version-2 Global Precipitation Climatology Project (GPCP) monthly precipitation analysis (1979-present), J. Hydrometeor., 4, 11471167, 2003.

Aznar, R., Sotillo, M. G., Martin, M. L., Somot, S., and Valero, F.: Comparison of model and satellite-derived longterm precipitation databases over the Mediterranean Basin: a general overview, Atmos. Res., 97, 170-184, 2010.

Bartholy, J., Pongracz, R., and Pattanyus-Abraham M.: Analyzing the genesis, intensity and tracks of western Mediterranean cyclones, Theor. Appl. Climatol., 96, 133-144, 2009.

Bennartz, R. and Petty, G. W.: The sensitivity of microwave remote sensing observations of precipitation to ice particle size distributions, J. Appl. Met. Clim., 40, 345-364, 2001.

Buehler, S. A. and John, V. O.: A simple method to relate microwave radiances to upper tropospheric humidity. J. Geophys. Res., 110, D02110, doi:10.1029/2004JD005111, 2005.

Buehler, S. A., Kuvatov, M., and John, V. O.: Scan asymmetries in AMSU-B data, Geophys. Res. Lett., 32, L248110, doi:10.1029/2005GL024747, 2005.
Campins, J., Genoves, A., Jansa, A., Guijarro, J. A., and Ramis, C.: A catalogue and a classification of surface cyclones for the Western Mediterranean, Int. J. Climatol., 20, 969-984, 2000.

Chaboureau, J.-P. and Claud, C.: Satellite-based climatology of Mediterranean cloud systems and their association with large-scale circulation, J. Geophys. Res., 111, D01102, doi:10.1029/2005JD006460, 2006.

Chaboureau, J. P., Cammas, J. P., Mascart, P., Pinty, J. P., Claud, C., Roca, R., and Morcrette, J. J.: Evaluation of a cloud system life-cycle simulated by Meso-NH during FASTEX using METEOSAT radiances and TOVS-3I cloud retrievals, Q. J. R. Meteorol. Soc., 126, 1735-1750, 2000.

Chaboureau, J.-P., Pantillon, F., Lambert, D., Richard, E., and Claud, C.: Tropical transition of a Mediterranean storm by jet crossing, Q. J. R. Meteorol. Soc., doi:10.1002/qj.960, in press, 2012.

Claud, C., Alhammoud, B., Funatsu, B. M., and Chaboureau, J.-P.: Mediterranean hurricanes: large-scale environment and convective and precipitating areas from satellite microwave observations, Nat. Hazards Earth Syst. Sci., 10, 2199-2213, doi:10.5194/nhess-10-2199-2010, 2010.

Dee, D. P., Uppala, S. M., Simmons, A. J., Berrisford, P., Poli, P., Kobayashi, S., Andrae, U., Balmaseda, M. A., Balsamo, G., Bauer, P., Bechtold, P., Beljaars, A. C. M., van de Berg, L., Bidlot, J., Bormann, N., Delsol, C., Dragani, R., Fuentes, M., Geer, A. J., Haimberger, L., Healy, S. B., Hersbach, H., Hólm, E. V., Isaksen, L., Kållberg, P., Köhler, M., Matricardi, M., McNally, A. P., Monge-Sanz, B. M., Morcrette, J.-J., Park, B.-K., Peubey, C., de Rosnay, P., Tavolato, C., Thépaut, J.-N., and Vitart, F.: The ERA-Interim reanalysis: configuration and performance of the data assimilation system, Q. J. R. Meteorol. Soc., 137, 553597, doi:10.1002/qj.828, 2011.

Deeter, M. N. and Vivekanandan, J.: AMSU-B observations of mixed-phase clouds over land, J. Appl. Meteor., 44, 72-85, 2005.

Di Tomaso, E., Romano, F., and Cuomo, V.: Rainfall estimation from satellite passive microwave observations in the range $89 \mathrm{GHz}$ to $190 \mathrm{GHz}$, J. Geophys. Res., 114, D18203, doi:10.1029/2009JD011746, 2009.

Drobinski, P., Ducrocq, V., and Lionello P.: Studying the hydrological cycle in the Mediterranean, EOS Trans. Am. Geophys. Union, 91, p. 373, doi:10.1029/2010EO410006, 2010.

Drobinski, P., Ducrocq, V., Lionello, P., and Homar, V. : HyMeX, the newest GEWEX regional hydroclimate project, GEWEX Newsletter, 21, 10-11, 2011.

Drobinski, P., Anav, A., Lebeaupin Brossier, C., Samson, G., Stéfanon, M., Bastin, S., Baklouti, M., Béranger, K., Beuvier, J., Bourdallé-Badie, R., Coquart, L., D’Andrea, F., De Noblet-Ducoudré, N., Diaz, F., Dutay, J.C., Ethe, C., Foujols, M.A., Khvorostyanov, D., Madec, G., Mancip, M., Masson, S., Menut, L., Palmieri, J., Polcher, J., Turquety, S., Valcke, S., and Viovy, N.: Modelling the Regional Coupled Earth system (MORCE): application to process and climate studies in vulnerable regions, Environ. Model. Softw., in press, doi:10.1016/j.envsoft.2012.01.017, 2012.

Fischer, E. M., Seneviratne, S. I., Luthi, D., and Schar, C.: Contribution of land-atmosphere coupling to recent European summer heat waves, Geophys. Res. Lett., 34, L06707, doi:10.1029/2006GL029068, 2007.

Flocas, H. A., Simmonds, I., Kouroutzoglou, J., Keay, K., Hat- 
saki, M., Bricolas V., and Asimakopoulos, D.: On cyclonic tracks over the Eastern Mediterranean, J. Climate, 23, 52435257, doi:10.1175/2010JCLI3426.1, 2010.

Frei, C. and Schär, C.: A precipitation climatology of the Alps from high-resolution rain-gauge observations, Int. J. Climatol., 18, 873-900, 1998.

Funatsu, B. M., Claud, C., and Chaboureau, J. P.: Potential of Advanced Microwave Sounding Unit to identify precipitating systems and associated upper-level features in the Mediterranean region: Case studies, J. Geophys. Res., 112, D17113, doi:10.1029/2006JD008297, 2007.

Funatsu, B. M., Claud, C., and Chaboureau, J. P.: A 6-year AMSUbased climatology of upper-level troughs and associated precipitation distribution in the Mediterranean region, J. Geophys. Res., 113, D15120, doi:10.1029/2008JD009918, 2008.

Funatsu, B. M., Claud, C., and Chaboureau, J. P.: Comparison between the large-scale environments of moderate and intense precipitating systems in the Mediterranean region, Mon. Weather Rev., 137, 3933-3959, doi:10.1175/2009MWR2922.1, 2009.

Gaertner, M. A., Jacob, D., Gil, V., Dominguez, M., Padorno, E., Sanchez, E., and Castro, M.: Tropical cyclones over the Mediterranean Sea in climate change simulations, Geophys. Res. Lett., 34, L14711, doi:10.1029/2007GL029977, 2007.

Giorgi, F.: Climate change hot-spots, Geophys. Res. Lett., 33, L08707, doi:10.1029/2006GL025735, 2006.

Goodrum, G., Kidwell, K., and Winston, W.: NOAA KLM User's Guide, US Dept. of Commerce, National Oceanic and Atmospheric Administration, National Environmental Satellite Data and Information Service, 2000.

Greenwald, T. J. and Christopher, S. A.: Effect of cold clouds on satellite measurements near $183 \mathrm{GHz}$, J. Geophys. Res., 107, 4170, doi:10.1029/2000JD000258, 2002.

Hong, G., Heygster, G., Miao, J., and Kunzi, K.: Detection of tropical deep convective clouds from AMSU-B water vapor channels measurements, J. Geophys. Res., 110, D05205, doi:10.1029/2004JD004949, 2005.

Hulme, M., Barrow, E. M., Arnell, N. W., Harrison, P. A., Johns, T. C., and Downing, T. E.: Relative impacts of human-induced climate change and natural variability, Nature, 397, 688-691, 1999.

Jansa, A., Genoves, A., Picornell, M. A., Campins, J., Riosalido, R., and Carretero, O.: Western Mediterranean cyclones and heavy rain, Part 2: Statistical approach, Meteor. Appl., 8, 43-56, 2001.

John, V. O., Holl, G., Buehler, S. A., Candy, B., Saunders, R. W., and Parker, D. E.: Understanding inter-satellite biases of microwave humidity sounders using global simultaneous nadir overpasses, J. Geophys. Res., 117, D02305, doi:10.1029/2011JD016349, 2012.

Kain, J. S.: The Kain-Fritsch convective parameterization: An update, J. Appl. Meteorol., 43, 170-181, 2004.

Kleespies, T. J. and Watts, P.: Comparison of simulated radiances, Jacobians and linear error analysis for the Microwave Humidity Sounder and the Advanced Microwave Sounding Unit-B, Q. J. R. Meteorol. Soc., 132, 3001-3010, 2007.

Kongoli, C., Pellegrino, P., Ferraro, R., Meng, H., and Dean, C.: The utilization of the AMSU high frequency measurements for improved coastal rain retrievals, Geophys. Res. Lett., 34, L17809, doi:10.1029/2007GL029940, 2007.

Lafore, J. P., Stein, J., Asencio, N., Bougeault, P., Ducrocq, V., Duron, J., Fischer, C., Héreil, P., Mascart, P., Masson, V., Pinty,
J. P., Redelsperger, J. L., Richard, E., and Vilà-Guerau de Arellano, J.: The Meso-NH Atmospheric Simulation System. Part I: adiabatic formulation and control simulations, Ann. Geophys., 16, 90-109, doi:10.1007/s00585-997-0090-6, 1998.

Laviola, S. and Levizzani, V.: Observing precipitation by means of water vapor absorption lines: a first check of the retrieval capabilities of the 183-WSL rain retrieval method, Italian J. Remote Sens., 41, 39-49, 2009.

Laviola, S. and Levizzani, V.: The 183-WSL fast rain rate retrieval algorithm, Part I: Retrieval design, Atmos. Res., 99, 443-461, 2011.

Lebeaupin Brossier, C., Béranger, K., Deltel, C., and Drobinski, P.: The Mediterranean response to different space-time resolution atmospheric forcings using perpetual mode sensitivity simulations, Ocean Model., 36, 1-25, 2011.

Lima, W. F. A., Machado, L. A. T., Morales, C. A., and Viltard, N.: Rainfall sensitivity analyses for the HSB sounder: an Amazon case study, Int. J. Remote Sens., 28, 3520-3545, doi:10.1080/01431160601013526, 2007.

Madec, G.: NEMO ocean engine, Note du Pole de modélisation, Institut Pierre-Simon Laplace (IPSL), France, No 27, ISSN No 1288-1619, 2008.

Mariotti, A., Struglia, M., Zeng, N., and Lau, K.: The hydrological cycle in the Mediterranean region and implications for the water budget of the Mediterranean Sea, J. Climate, 15, 1674-1690, 2001.

Meirold-Mautner, I., Prigent, C., Defer, E., Pardo, J.-R., Chaboureau, J.-P., Pinty, J.-P., Mech, M., and Crewell, S.: Radiative transfer simulations using mesoscale cloud model outputs: comparisons with passive microwave and infrared satellite observations for mid-latitudes, J. Atmos. Sci., 64, 1550-1568, 2007.

Mo, T.: AMSU-A antenna pattern corrections, IEEE Trans. Geosci. Remote Sens., 37, 103-112, 1999.

Mo, T.: Calibration and validation of the NOAA-18 Microwave radiometers, IEEE MicroRad, 24-28, 2006.

Saunders, R. W., Matricardi, M., Brunel, P., English, S., Bauer, P., O'Keeffe, U., Francis, P., and Rayer, P.: RTTOV-8 Science and Validation Report, Technical Report, Numer. Weather Predic. Satell. Appl. Facil., Exeter, UK, 41 pp., 2005.

Skamarock, W. C., Klemp, J. B., Dudhia, J., Gill, D. O., Barker, D. M., Duda, M. G., Huang, X-Y., Wang, W., and Powers, J. G.: A description of the Advanced Research WRF Version 3, NCAR Tech. Note NCAR/TN-475+STR, 125 pp., 2008.

Surussawadee, C. and Staelin, D. H.: Satellite retrievals of Arctic and Equatorial rain and snowfall rates using Millimeter Wavelengths, IEEE Trans. Geosci. Remote Sens., 47, 3697-3707, doi:10.1109/TGRS.2009.2029093, 2009.

Surussawadee, C. and Staelin, D.H.: Global precipitation retrievals using the NOAA AMSU Millimeter-Wave Channels: Comparisons with rain gauges, J. Appl. Met. Clim., 49, 124-135, doi:10.1175/2009JAMC2262.1, 2010.

Trigo, I. F., Bigg, G. R., and Davies, T. D.: Climatology of cyclogenesis mechanisms in the Mediterranean, Mon. Weather Rev., 130, 549-569, 2002.

Valcke, S.: OASIS3 User Guide (prism $\backslash 2-5$ ), CERFACS Technical Report TR/CMGC/06/73, PRISM Report No 3, Toulouse, France, 60 pp., 2006.

Vila, D., Ferraro, R., and Joyce, R. : Evaluation and improvement of 
AMSU precipitation retrievals, J. Geophys. Res., 112, D20119, doi:10.1029/2007JD008617, 2007.

Wiedner, M., Prigent, C., Pardo, J. R., Nuissier, O., Chaboureau, J.P., Pinty, J.-P., and Mascart, P.: Modeling of passive microwave responses in convective situations using output from mesoscale models: Comparison with TRMM/TMI satellite observations, J. Geophys. Res., 109, D06214, doi:10.1029/2003JD004280, 2004.
Xie, P. and Arkin, P. A.: Analyses of global monthly precipitation using gauge observations, satellite estimates, and numerical model predictions, J. Climate, 9, 840-858, 1996.

Ziv, B., Saaroni, H., and Alpert, P.: The factors governing the summer regime of the eastern Mediterranean, Int. J. Climatol., 24, 1859-1871, 2004. 